\title{
AS PESQUISAS NO PARQUE ESTADUAL CUNHAMBEBE COM DESTAQUE PARA A EDUCAÇÃO AMBIENTAL E O PATRIMÔNIO HISTÓRICO E CULTURAL: RESULTADOS DE UMA REVISÃO SISTEMÁTICA INTEGRATIVA
}

Hedinene Costa $^{1}$

Daniel Fonseca de Andrade ${ }^{2}$

Resumo $O$ objetivo deste trabalho é identificar os tipos de pesquisas produzidas no Parque Estadual Cunhambebe e analisar qual o enfoque de pesquisa é atribuído para a Educação Ambiental e o patrimônio histórico e cultural da unidade de conservação e de seu entorno. Foi realizada uma revisão sistemática integrativa da literatura. Os 26 resultados foram organizados em nove categorias: biodiversidade, conflitos, geoconservação, gestão de unidades de conservação, serviços ambientais, uso público, recursos hídricos, Educação Ambiental e patrimônio histórico e cultural. Os resultados apontaram que trabalhos sobre a perspectiva da valorização do patrimônio histórico e cultural, e sobre Educação Ambiental ainda são escassos no parque.

Palavras-chave: Unidade de Conservação; Mangaratiba; Conscientização Ambiental

\footnotetext{
${ }^{1}$ Universidade Federal do Estado do Rio de Janeiro. E-mail:hedinenerocha@gmail.com, Link para o Lattes: http://lattes.cnpq.br/1401141089379631

2 Universidade Federal do Estado do Rio de Janeiro. E-mail: Daniel.andrade@unirio.br. Link para o Lattes: http://lattes.cnpq.br/7825501663911868
} 
Abstract The objective of this work is to identify the types of research that have been produced in the State Park Cunhambebe and analyze which research focus is attributed to environmental education and to the historical and cultural heritage found in the park and its surroundings. The methodological path was composed of a systematic integrative literature review. The 26 results were organized into nine categories: biodiversity, conflicts, geoconservation, protected area management, environmental services, public use, water resources, environmental education, and historical and cultural heritage. It was found that research on the value of historical and cultural heritage, and on environmental education are still scarce in the State Park Cunhambebe.

Keywords: Protected Areas; Mangaratiba; Environmental Awareness.

\section{Introdução}

O Parque Estadual Cunhambebe (PEC) é uma unidade de conservação (UC) de proteção integral, criada através do Decreto Estadual no 41.358, de 13 de junho de 2008 (RIO DE JANEIRO, 2008). Esse decreto segue princípios inseridos no artigo no 225 da Constituição da República Federativa do Brasil (BRASIL, 1988) e se apoia na definição da Mata Atlântica como patrimônio nacional. Além disso, se fundamenta na importância de serviços ambientais proporcionados pelas florestas para o desenvolvimento econômico e social, e para a vida das populações tradicionais (INEA, 2015).

O PEC está localizado no litoral sul do estado do Rio de Janeiro, com 38.053 hectares e aproximadamente $463 \mathrm{~km}$ de extensão. Seu território integra, parcialmente, quatro municípios da região da Costa Verde, da região do Médio Paraíba do Sul e da Região Metropolitana do Rio de Janeiro: Mangaratiba, Angra dos Reis, Rio Claro e Itaguaí. Ademais, a UC tem seu limite com o município de Bananal/SP (INEA, 2015).

O PEC é a segunda maior UC de proteção integral sob a gestão do Estado do Rio de Janeiro. Sua implantação se justificou como forma de assegurar regionalmente a preservação da Mata Atlântica, evitar perda de biodiversidade e a degradação dos recursos hídricos. O PEC compõe o mosaico de unidades de conservação que forma o Corredor Ecológico TinguáBocaína, e está inserido na zona núcleo 1 da Reserva da Biosfera de Mata Atlântica (INEA, 2015).

A criação de espaços territoriais especialmente protegidos, como as UC, constitui-se como um instrumento de gestão territorial previsto na Política Nacional do Meio Ambiente (BRASIL, 1981). Elas visam conservar a vida na floresta, proteger as características relevantes da natureza geológica e cultural, favorecer condições para a realização de atividades de educação e interpretação ambiental, e incentivar a pesquisa e o monitoramento ambiental (BRASIL, 2000). 
A realização de pesquisas em UC, além de um valor em si, pode fortalecer seus programas de educação e interpretação ambiental. Da mesma maneira, pode favorecer a valorização do patrimônio histórico e cultural da região. Também pode promover a integração dos visitantes e das comunidades que vivem no entorno, estimulando ações e reflexões sobre as questões ambientais inerentes ao uso desses espaços e a conservação da biodiversidade (MMA, 2006).

Unidades de conservação são ambientes privilegiados para o estímulo à reflexão e a construção de novas mentalidades (OLIVEIRA et al., 2021). De acordo com as diretrizes para Estratégia de Comunicação e Educação Ambiental em Unidades de Conservação (ENCEA), a inserção das UC em processos educativos pode ser consolidada mediante o fortalecimento da sua relação com pesquisadores e com instituições de ensino e pesquisa. Isso é possível através da articulação de ações de comunicação e Educação Ambiental, por meio da elaboração, desenvolvimento e a divulgação de resultados de pesquisas que estimulem 0 retorno desses às populações $e$ comunidades locais (MMA, 2006). Além disso, a Educação Ambiental nas unidades de conservação tem o papel de cobrir lacunas de informação e aproximar os principais atores sociais que de alguma forma se relacionam com a UC (INEA, 2014).

Nesse contexto, o presente trabalho tem como objetivos identificar os tipos de pesquisas que são produzidas no PEC e analisar qual o enfoque de pesquisa é atribuído para a Educação Ambiental e o patrimônio histórico e cultural encontrado na UC e no seu entorno. Esta pesquisa visa colaborar com o planejamento estratégico contido no Plano de Manejo do PEC, que tem entre os seus objetivos desenvolver programas e ações que contribuam para fomentar a pesquisa, fortalecer o monitoramento ambiental, estimular a recreação, promover a Educação Ambiental e incentivar alternativas de desenvolvimento regional (INEA, 2015).

\section{Metodologia}

O caminho metodológico escolhido para este estudo foi uma revisão sistemática da literatura do tipo integrativa.

A revisão sistemática é um tipo de investigação científica que tem o propósito de conciliar, avaliar e coordenar uma síntese de resultados de múltiplos estudos primários. Além disso, visa responder a uma pergunta, utilizando métodos sistemáticos para discernir, selecionar e avaliar pesquisas pertinentes, e posteriormente coletar e analisar dados dos estudos incluídos na revisão (CORDEIRO, 2007).

O termo "integrativa" provém da integração de teorias, conceitos ou ideias procedentes das pesquisas utilizadas no método (BOTELHO; CUNHA; MACEDO, 2011). Esse método caracteriza-se pelo uso da metodologia com 
rigor científico e grande transparência, visando evitar parcialidade na seleção dos textos (RAMOS; FARIA; FARIA, 2014).

Assim, a revisão integrativa é uma forma de pesquisa que sistematiza os resultados de estudos concernentes a um determinado tema de maneira integrada. Além disso, permite sintetizar e tecer conclusões gerais sobre o assunto pesquisado e, ao incorporar estudos, contribui para gerar novas concepções e perspectivas acerca do tema revisado, e indicar possíveis lacunas (TORRACO, 2005).

O processo de revisão de literatura, ao ser descrito no traçado metodológico da investigação, deve explicitar o modo como foram buscadas, examinadas e distinguidas as fontes utilizadas no estudo. Nesse sentido, é importante que se descrevam as etapas percorridas e que se especifiquem os procedimentos utilizados (RAMOS; FARIA; FARIA; 2014). No presente trabalho, os passos metodológicos foram: i) estabelecimento do tema e das perguntas norteadoras; ii) o teste e definição da equação de pesquisa e do âmbito temático a ser utilizado; iii) a definição preliminar dos critérios de inclusão e exclusão; iv) identificação dos estudos pré-selecionados e selecionados; v) coleta de dados; vi) categorização dos estudos e análise dos dados; vii) Interpretação e apresentação dos resultados. O fluxo das etapas conforme realizadas neste estudo está presente na Figura 1, abaixo.

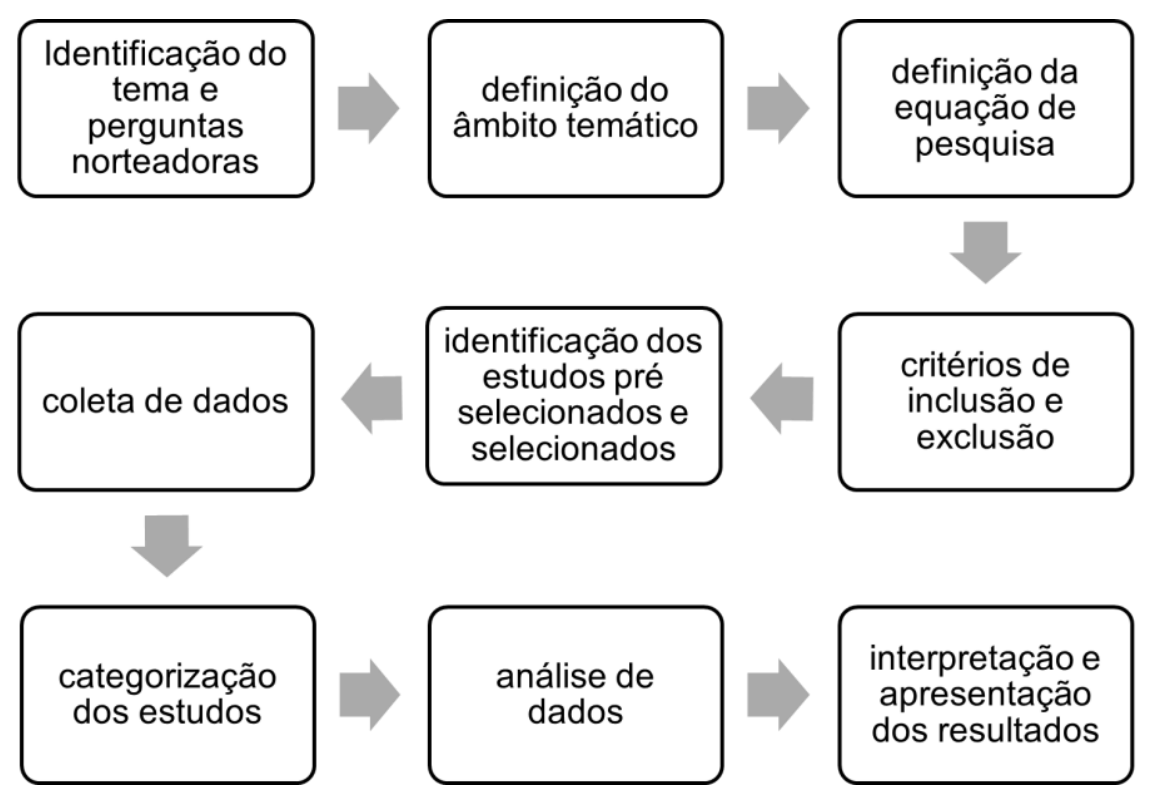

Figura 1: Etapas da Revisão Integrativa.

Fonte: Os autores. 


\section{Resultados e Discussão}

Conforme visto acima, as perguntas que orientaram esta pesquisa foram: Quais os tipos de pesquisas que são produzidas no PEC? Qual o enfoque de pesquisa é atribuído para a Educação Ambiental? Qual o enfoque de pesquisa é atribuído ao patrimônio histórico e cultural encontrado na UC e no seu entorno?

A pesquisa foi iniciada no dia vinte de março de 2021. O descritor escolhido para tal foi "Parque Estadual Cunhambebe", em português, e a base indexadora foi o "Google Acadêmico", já que testes anteriores utilizando o mesmo descritor em outras bases (Periódico Capes e Web of Science) não forneceram resultados suficientes para que os objetivos da pesquisa fossem respondidos. Quanto ao caminho da pesquisa no portal selecionado, optou-se por iniciar o processo em "busca avançada" e acolher os trabalhos em "qualquer idioma", de forma a poder circunscrever, da maneira mais ampla possível, o objeto em estudo.

Os critérios de exclusão e inclusão de trabalhos que encaminharam a seleção de dados foram os seguintes: para a exclusão, os trabalhos que não corresponderam às perguntas norteadoras, textos repetidos e trabalhos que apenas citaram, mas não desenvolveram, o descritor. Para inclusão, foi selecionado o ano de criação da unidade de conservação (2008) e estudos que tivessem o Parque Estadual Cunhambebe como objeto da pesquisa.

O recorte temporal para a seleção dos textos foi do ano de 2008 a março de 2021, período específico definido em função da data de criação da unidade de conservação até o momento de início da pesquisa. Por fim, os resultados obtidos foram transferidos da base indexadora para uma pasta de armazenamento interno e foram codificados alfanumericamente, para organização e identificação dos estudos pré-selecionados e selecionados (BOTELHO, 2011). Essa organização auxiliou na análise em separado de cada um deles e o resguardo de suas diferenças.

A análise foi iniciada com a leitura dos títulos dos trabalhos e, a partir disso, foram eliminados os trabalhos que não corresponderam às perguntas norteadoras, por se referirem a pesquisas em outros Estados e unidades de conservação, e aqueles que apenas citaram o descritor no título.

Os trabalhos selecionados com base na leitura dos títulos tiveram os seus resumos analisados, e aqueles que responderam positivamente aos critérios de inclusão foram destacados para posteriormente serem lidos integralmente. Mais uma vez, os critérios de inclusão e exclusão foram acionados. Por fim, os dados extraídos dos trabalhos selecionados, a partir das perguntas orientadoras, foram organizados em uma matriz de síntese, para sua categorização geral e análise (BOTELHO, 2011).

A amostra inicial levantada da pesquisa na base indexadora "Google Acadêmico", seguindo-se a equação descrita acima, constou de 86 resultados. Após análise dos títulos dos trabalhos, foram selecionados 66 trabalhos. Entre

revista brasileira educação ambiental 
as exclusões nessa etapa, a maior parte ocorreu ou porque a abrangência dos estudos não se referiu à UC pesquisada, ou porque os trabalhos eram repetidos em outro idioma. Posteriormente, os 66 trabalhos pré-selecionados foram mais uma vez analisados, desta vez com a leitura de seus resumos. Aqui foi constatado que, dos 66 trabalhos, 40 apenas mencionavam o descritor "Parque Estadual Cunhambebe" sem, no entanto, constar de pesquisas realizadas na localidade. Os 26 trabalhos remanescentes foram, então, lidos na íntegra e corresponderam a todos os critérios de inclusão e aos objetivos da pesquisa, tornando-se assim o corpus de trabalho desta pesquisa. A Tabela 1, abaixo, traz um resumo das etapas de análise e exclusão dos textos.

Tabela 1: Número de publicações inclusas na revisão integrativa por etapas de seleção e base indexadora, com base no descritor Parque Estadual Cunhambebe.

\begin{tabular}{cc}
\hline Trabalhos Acadêmicos & Base Indexadora/ Google Acadêmico \\
\hline Amostra inicial (após aplicação do descritor) & 86 \\
\hline Selecionados após leitura do título & 66 \\
\hline Selecionados após leitura dos resumos & 26 \\
\hline $\begin{array}{c}\text { Selecionados pela leitura completa e por } \\
\text { corresponder os critérios de inclusão }\end{array}$ & 26 \\
\hline Amostra final & 26 \\
\hline
\end{tabular}

Fonte: Os autores.

O munícipio de Mangaratiba é a região que compõe a unidade de conservação que contém a maior parte dos estudos identificados, 12, possivelmente em decorrência de ser o município com a maior sobreposição de área com a UC, cerca de $42 \%$. É também a região onde está localizada a sede do parque, no bairro do Vale do Sahy. Segue-se à Mangaratiba, o município de Itaguaí, com 2 trabalhos. Porém, 12 publicações não especificam a área em que foram realizadas, mas abordam o PEC de forma integral.

A maioria dos trabalhos acadêmicos que compõem o escopo de análise desta revisão integrativa é formada por artigos publicados em revistas científicas (13), seguidos de dissertações (5) e monografias (4). Relatos de experiência, resumos expandidos, relatórios técnicos e capítulos de livro, contaram com um trabalho cada (Tabela 2).

Tabela 2: Tipos de trabalhos acadêmicos incluídos na Revisão Integrativa.

\begin{tabular}{lc}
\hline \multicolumn{1}{c}{ Tipos de trabalhos acadêmicos } & Base Indexadora Google Acadêmico \\
\hline Artigos em revistas científicas & 13 \\
\hline Dissertações & 5 \\
\hline Monografias & 4 \\
\hline Relato de Experiência & 1 \\
\hline Resumo Expandido & 1 \\
\hline Relatório técnico & 1 \\
\hline Capítulo de livro & 1 \\
\hline Amostra Final & 26 \\
\hline
\end{tabular}

Fonte: Os autores. 
As publicações selecionadas na base indexadora Google Acadêmico estão concentradas entre os anos de 2013 e 2019, sendo que os anos de 2017 e 2019 se destacaram com o maior número de trabalhos acadêmicos publicados. Embora a data de criação do parque, o ano de 2008, tenha sido utilizada como critério de inclusão, as publicações só apareceram no levantamento a partir do ano de 2013, demonstrando que as pesquisas na UC são recentes. Esse hiato de cinco anos antes da primeira publicação pode representar a lacuna entre a criação do parque, o início de pesquisas e o tempo demandado para sua integralização e publicação.

Quanto aos tipos de pesquisas encontrados por esta investigação, realizadas no PEC no intervalo de tempo estudado, os trabalhos foram organizados por afinidade de áreas de estudos em 9 categorias (Figura 2): biodiversidade, geoconservação, serviços ambientais, gestão de UC, patrimônio histórico e cultural, conflitos, recursos hídricos, uso público, Educação Ambiental. Esse panorama demonstra que o PEC e seu entorno são interessantes como objeto para uma ampla gama de áreas do conhecimento, ou seja, do ponto de vista acadêmico, é uma UC de importância interdisciplinar.

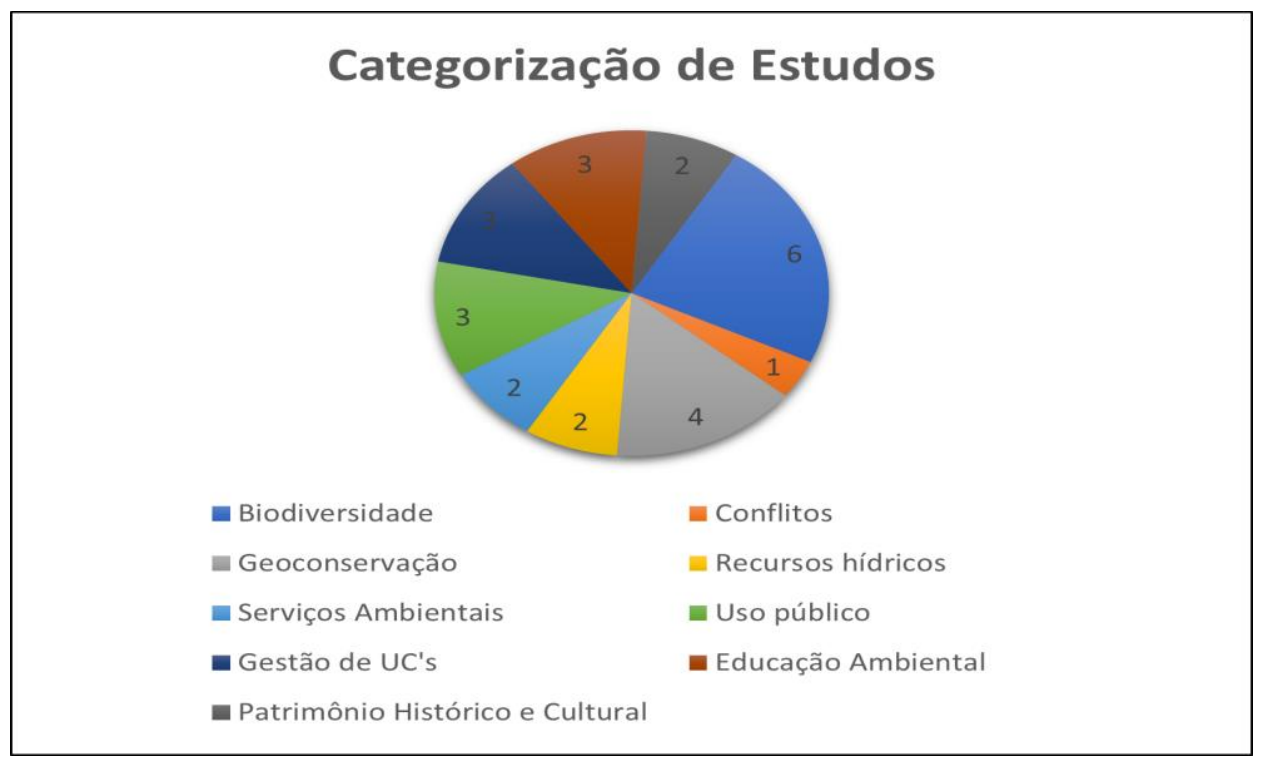

Figura 2 Gráfico de categorização dos estudos selecionados.

Fonte: Os autores.

$\mathrm{Na}$ categoria biodiversidade, correlacionamos 6 trabalhos (COSTA, 2019; GONÇALVES, 2019; LIMA et al., 2013; MAURENZA et al., 2018; ROCHA; ROCHA, 2019a; ROCHA; ROCHA, 2019b), ou seja, quase um quarto do total de estudos identificados. Destacam-se nessa categoria estudos com enfoque no levantamento e identificação de novas espécies, e a produção de novos conhecimentos sobre a flora e a fauna. Os trabalhos apresentam levantamentos de espécies de invertebrados e vertebrados, investigações que identificam espécies endêmicas e exóticas, e trabalhos que contribuem com o monitoramento de espécies ameaçadas. 
A categoria conflitos foi formada por 1 estudo (ANTUNES, 2017), que investiga conflitos territoriais em áreas protegidas. No caso do PEC, as tensões ocorrem por conta do uso conflitante do solo devido à sobreposição de políticas públicas: a área do parque, delimitada por uma política de conservação da biodiversidade, é parcialmente sobreposta à uma área de assentamento rural de reforma agrária, chamada de Fazenda Rubião. O estudo reúne documentos inéditos que podem contribuir com processos participativos de tomada de decisão e estratégias de gestão territorial participativa. Da mesma forma, identifica a ausência de interação e comunicação entre os representantes do poder público, associações e produtores locais como fatores que dificultam a gestão de conflitos territoriais no PEC (ANTUNES, 2017).

$\mathrm{Na}$ categoria geoconservação foram incluídos 4 trabalhos (RANGEL, 2016; RANGEL; BOTELHO, 2017; RANGEL et al., 2017; SOUZA, 2019). Esses estudos abordam questões referentes ao ordenamento de trilhas, a análise de fragmentação territorial, e o mapeamento de geossítios e seu potencial para o geoturismo. Enfatizam também a importância de práticas de Educação Ambiental na visitação e para a conservação dos geossítios.

Formando a categoria recursos hídricos, reunimos 2 estudos que revelam interesses de pesquisa concernentes à avaliação da sustentabilidade hídrica e gestão dos recursos hídricos (INEA, 2018; MATIAS, 2016). Cabe destacar a relevância do PEC na preservação de nascentes e dos mananciais hídricos da região (INEA, 2015).

A categoria serviços ambientais foi composta com a inclusão de 2 trabalhos que apresentam avaliações sobre as percepções da comunidade do entorno do PEC. Os estudos versam sobre os valores dos serviços ecossistêmicos e sua contribuição para uma gestão baseada em valores locais. Além disso, retratam a influência dos pagamentos por serviços ambientais como instrumento para a conservação (COELHO JUNIOR et al., 2021; GONZAGA, 2016).

Integram a categoria uso público, 3 estudos (FLOR et al., 2018; ROSA, 2017; SANTOS et al., 2019), que abordam questões relativas ao ordenamento da visitação e parcerias público privadas na gestão do uso público, além do estímulo às alternativas de desenvolvimento através do turismo planejado no PEC.

Agrupamos na categoria gestão de UC, 3 estudos (FERREIRA, 2015; VIANA et al., 2016; OLIVEIRA, 2017) em que os autores discutem a avaliação da efetividade de gestão do Mosaico Bocaina, do qual o PEC é integrante, e abordam propostas de aprimoramento de modelos de gestão integrada de território. Além disso, os estudos apresentam investigações sobre a defaunação, visto que a caça é um dos problemas que predominam na unidade de conservação (INEA, 2015). A ignorância sobre o papel das espécies nos ecossistemas, aliada a forte pressão de caça sobre as populações de espécies diversas, configuram-se como as principais ameaças aos animais silvestres. 
Destacamos que a Educação Ambiental é abordada no estudo como um dos caminhos para superar essa questão (FERREIRA, 2015).

As duas categorias remanescentes, Educação Ambiental e patrimônio histórico e cultural, como foram relacionadas a um objetivo específico da pesquisa, serão tratadas de forma particular, na seção seguinte.

\section{O enfoque da Educação Ambiental e Patrimônio histórico e cultural nas pesquisas realizadas no Parque Estadual Cunhambebe}

A categoria Educação Ambiental foi composta por 3 trabalhos (LIMA, 2017; MARTINS et al., 2018 RAMALHO et al., 2019) com foco em pesquisas de Educação Ambiental realizadas na UC e no seu entorno. Em linhas gerais, esses trabalhos abordam a divulgação de projetos, análises e avaliações de programas, e relatos de ações de Educação Ambiental nas escolas do entorno do parque.

Dos estudos que foram inseridos na categoria Educação Ambiental, 1 apresenta o enfoque da Educação Ambiental nas escolas do município de Itaguaí (RJ), no entorno do PEC (LIMA, 2017). Esse trabalho conclui que programas de Educação Ambiental são desenvolvidos em escolas municipais que estão no entorno do PEC, porém, de forma teórica e sem apoio interno ou externo. A pesquisa identifica a falta de integração das secretarias e as unidades escolares como sendo uma lacuna que caracteriza as iniciativas de Educação Ambiental feitas na região. Além disso, apresenta a falta de recursos financeiros e recursos humanos qualificados como dificuldades enfrentadas pelas escolas municipais no entorno do PEC para implantação de projetos de Educação Ambiental.

Ainda nesse estudo, das oito escolas que participaram da avaliação feita pela autora, seis possuíam conhecimento da existência do PEC, porém, não tinham conhecimento de que estavam no entorno da UC. Apenas uma escola havia participado de ações de Educação Ambiental do PEC, na própria unidade escolar, e nenhuma escola havia realizado visita na sede ou área do PEC (LIMA, 2017).

Por outro lado, o segundo estudo (MARTINS, et al., 2018), também relacionado com a categoria de Educação Ambiental, apresenta o enfoque no desenvolvimento de processos educativos crítico-reflexivos. No texto, as autoras ressaltam a parceria consolidada da escola com os guardas-parques do PEC para as ações de Educação Ambiental e a importância das aulaspasseio realizadas na UC.

Esse trabalho é fruto de uma mobilização da Escola Municipal Vale do Sahy, localizada no município de Mangaratiba (RJ), que se propôs implementar as diretrizes que estão descritas no seu Projeto Político Pedagógico (PPP). A escola está localizada próximo à sede do PEC, o que facilitou a realização de aulas-passeio. Essas aulas foram geradoras de questionamentos ambientais 
relativos a impactos ambientais, preservação, ecossistema, fauna, geografia e história local. As autoras destacam no trabalho a parceria entre o PEC e a escola, que já existe há anos, e o trabalho desenvolvido de conscientização com os estudantes. Também relatam o aprendizado de conceitos básicos como unidade de conservação, preservação, entre outros. Além disso, enfatizam o compromisso da escola assumido com os estudantes, de auxiliá-los no desenvolvimento de protagonismo para construir conhecimento (MARTINS et al., 2018).

Ainda sobre a categoria Educação Ambiental, o terceiro trabalho (RAMALHO et al., 2019) faz parte de um projeto que busca fortalecer as práticas de Educação Ambiental no PEC e na Área de Proteção Ambiental de Mangaratiba (APAMAN), que tem parte de seu território sobreposto a área do PEC. A pesquisa apresentou os resultados preliminares de um diagnóstico participativo aplicado aos professores das escolas do município de Mangaratiba com o objetivo de entender o conhecimento e a necessidade dos professores em relação ao parque.

O diagnóstico é parte do projeto "A Escola e o Parque Estadual Cunhambebe e a APAMAN: Depende de nós Preservar", que possui a parceria da Associação Água Marinha, da Universidade Federal Rural do Rio de Janeiro (UFRRJ) e Universidade Estadual do Rio de Janeiro (UERJ). Os dados do diagnóstico foram obtidos através de um questionário semiestruturado que foi distribuído aos participantes no I Encontro de Educação, Cultura, da Agricultura e o Parque Estadual Cunhambebe e a APAMAN, no município de Mangaratiba em 2018.

Nesse encontro, obteve-se a participação de cento e três profissionais de 37 escolas convidadas, dos quais 43 responderam ao questionário. As questões foram estruturadas em torno dos temas: unidade de conservação, recursos hídricos, resíduos sólidos, conservação da paisagem e desafios da Educação Ambiental.

O diagnóstico apresenta os principais problemas ambientais em Mangaratiba, percebidos pelos professores. No que tange a Educação Ambiental, a falta de recursos é destacada como principal entrave para desenvolver as práticas de Educação Ambiental nas escolas. Contudo, a falta de integração entre os atores sociais que compõem a rede de ensino é apontada no estudo como principal dificuldade para efetivar os programas de Educação Ambiental nas escolas do município de Mangaratiba (RAMALHO, et al., 2019).

Além disso, o diagnóstico ressalta que apesar do PEC ser conhecido por alguns educadores, a maior parte não havia visitado ou participado de projetos desenvolvidos pela gestão. Da mesma forma, enfatiza a importância de se ter uma UC como ferramenta para futuros projetos de Educação Ambiental (RAMALHO et al., 2019). 
As pesquisas identificadas na categoria Educação Ambiental possuem enfoques semelhantes: trabalham com escolas do entorno do PEC e retratam os desafios na implementação de programas de Educação Ambiental nas unidades escolares. Também, ressaltam a importância das ações desenvolvidas na UC, mas apresentam a falta de interação entre gestores municipais, agentes educadores e as unidades escolares como um desafio na implementação e continuidade dos programas de Educação Ambiental. Por fim, concordam quanto ao potencial de processos educativos do PEC para a conservação.

Quanto aos estudos identificados na categoria patrimônio histórico e cultural, 2 estudos foram reunidos (RAMOS, 2013; SATYRO, 2013), que identificam o potencial da educação patrimonial para a conservação. Em geral, os textos retratam o abandono de sítios históricos em Mangaratiba, e a ausência de ligação afetiva relacionada a memória das edificações existentes.

De maneira mais específica, Ramos (2013) propõe uma reflexão sobre a preservação de sítios históricos integrados a UC. O trabalho faz uma abordagem sobre o conceito de 'monumento' como patrimônio cultural e sua contribuição na construção da identidade histórica, e pondera sobre a memória como elemento fundamental nessa construção. Aborda também a descaracterização dos monumentos históricos existentes e, apesar disso, reforça a necessidade de se rastrear suas histórias interpretando-as, mesmo que a sua descaracterização seja inevitável (RAMOS, 2013).

Neste contexto, o autor ilustra o debate com o caso da atual rodovia estadual RJ-149, um patrimônio histórico do PEC apresentado no estudo como um exemplo de vínculo entre a dimensão histórica e o patrimônio natural. A rodovia, que faz a conexão do município de Mangaratiba à Rio Claro, foi uma das primeiras estradas de rodagem do Império do Brasil. A antiga estrada de Mangaratiba a São João do Príncipe foi também muito utilizada por tropeiros, sendo, posteriormente, incorporada em parte ao traçado da estrada provincial, em meados do século XIX, e atualmente atravessa uma parte significativa de área do PEC (RAMOS, 2013).

Além disso, o trabalho menciona os esforços do órgão gestor do PEC, do Instituto Estadual do Ambiente (INEA) e de outras instituições privadas, na articulação de ações para transformar a via em estrada parque, com infraestrutura para a recepção de visitantes e realização de pesquisas voltadas para os aspectos históricos e arqueológicos, assim como de iniciativas de Educação Ambiental e patrimonial.

O segundo trabalho (SATYRO, 2013) apresenta um breve panorama dos patrimônios históricos e culturais que compõem o acervo patrimonial do município de Mangaratiba, entre os quais, complexos de ruínas e o Bebedouro da Barreira, que integram o patrimônio histórico do PEC, localizado na rodovia RJ 149 citada acima. 
O estudo aponta para a descaracterização e depredação dos patrimônios no município de Mangaratiba (RJ), e discorre sobre as divergências de opiniões sobre a preservação ou não desses patrimônios. Também, apresenta uma reflexão sobre a educação patrimonial como um dos possíveis caminhos para a minimização da depredação em áreas de preservação do patrimônio em Mangaratiba, e cita algumas ações de educação patrimonial que são realizadas nas escolas do município. Por fim, o trabalho sugere a educação patrimonial como uma poderosa ferramenta para alcançar uma das metas do Plano de Manejo (INEA, 2015) do PEC, a valorização do patrimônio histórico e cultural, visto que a UC apresenta no seu entorno e na sua área, diversos sítios históricos (SATYRO, 2013).

As pesquisas sobre patrimônio histórico e cultural caracterizam-se por apresentar a educação patrimonial como um instrumento importante para a conservação. Também apresentam demandas e estratégias que podem subsidiar ações de Educação Ambiental e de valorização do patrimônio histórico e cultural na UC e no seu entorno.

\section{Conclusões}

De acordo com os trabalhos levantados na base indexadora Google Acadêmico, as publicações no PEC são recentes, com início em 2013, e foram desenvolvidas em diversos campos de conhecimento, categorizados em nove áreas por este trabalho: biodiversidade, conflitos, geoconservação, gestão de UC, serviços ambientais, uso público, recursos hídricos, Educação Ambiental e patrimônio histórico e cultural. Esse cenário demonstra que o parque exerce interesse a pesquisadores de diversas áreas, que podem olhá-lo por diferentes lentes, com diferentes interesses e finalidades. Isso o caracteriza como um local de vocação interdisciplinar. Além disso, a diversidade de áreas de pesquisas encontrada afirma o potencial educador da UC, já que todo conhecimento produzido pode oferecer subsídios para projetos de Educação Ambiental emanados pelo PEC.

As pesquisas realizadas especificamente na categoria de Educação Ambiental são caracterizadas pelo enfoque nos programas de Educação Ambiental nas escolas do entorno e na interação com o PEC. Da mesma forma, essas pesquisas identificam lacunas como a falta de interação entre gestores públicos e unidades escolares, e a falta de recursos, como obstáculos para a execução de programas de Educação Ambiental. Também, explicitam a importância de práticas pedagógicas no PEC como instrumento de gestão e conservação. Uma questão relevante diagnosticada é o fato da maioria das escolas e docentes envolvidos nas pesquisas incluídas neste trabalho não terem visitado e nem participado de projetos realizados pelo PEC. Considerando que são escolas do entorno, essa lacuna se coloca como um relevante foco de investimento na Educação Ambiental promovida pelo parque. 
Já os estudos que compõem a categoria patrimônio histórico e cultural destacam como característica comum a necessidade de estudos e projetos que valorizem, contextualizem e promovam a (re)significação dos bens históricos, culturais e arqueológicos existentes na região de Mangaratiba.

Apesar do grande potencial existente na região, em função dos serviços ambientais proporcionados pelo PEC e do rico legado cultural, histórico e arqueológico do seu entorno, considera-se aqui que há, em linha gerais, poucas publicações envolvendo o PEC e o seu entorno. Da mesma maneira, considera-se que os trabalhos de pesquisa envolvendo a valorização do patrimônio cultural e histórico, e a Educação Ambiental, até o momento são escassos, ainda que os existentes deem pistas sobre os interesses primordiais de pesquisa na região e de algumas lacunas a serem investigadas.

Uma questão, no entanto, a ser destacada aqui que foi observada no âmbito desta pesquisa, é que para o PEC e seu entorno, devido às suas características ambientais, sociais e históricas peculiares, a Educação Ambiental e a valorização do patrimônio histórico e cultural devem ser vistas como indissociáveis. Juntas, permitem a compreensão do ambiente local não apenas a partir do enfoque biológico ou ecológico, mas deles situados historicamente, e que o rico acervo patrimonial presente colabora muito para tal. Essa indissociabilidade, inclusive, remete e reforça o caráter interdisciplinar da Educação Ambiental, e pode trazer mais relevância e sentido à existência da UC, além de maior identificação dela com as comunidades do entorno, e vice-versa. Para tal, é fundamental uma maior articulação entre os diferentes atores e instituições parceiros do PEC com vias à potencialização de suas ações e ampliação de suas capacidades de comunicação, entre si e com a sociedade em geral.

\section{Referências}

ANTUNES, E.P. Conflitos Territoriais em Áreas Protegidas do Sul Fluminense: o caso dos pequenos produtores familiares assentados no Parque Estadual Cunhambebe, Mangaratiba (RJ). Orientador: Augusto César Pinheiro da Silva; 2017. 154 f. Dissertação (Mestrado em Geografia) - Departamento de Geografia e Meio Ambiente PUC-Rio, 2017.

BRASIL. Constituição (1988). Constituição da República Federativa do Brasil. - Capítulo VI - do Meio Ambiente: Art. 225. Brasília, DF.

BRASIL. Lei Ordinária 6.938, de 31 de agosto de 1981. Dispõe sobre a política nacional do meio ambiente, seus fins e mecanismos de formulação e aplicação, e dá outras providências. Diário Oficial da União, 02/09/1981, p. 16509.

BOTELHO, L. L. R.; DE ALMEIDA CUNHA, C. C.; MACEDO, M. O método da revisão integrativa nos estudos organizacionais. Gestão e sociedade, v. 5, n. 11, p. 121-136, 2011. 
COELHO-JUNIOR, M. G. et al. Exploring Plural Values of Ecosystem Services: Local Peoples' Perceptions and Implications for Protected Area Management in the Atlantic Forest of Brazil. Sustainability, v. 13, n. 3, p. 1019, 2021.

CORDEIRO, A. M. et al. Revisão sistemática: uma revisão narrativa. Revista do Colégio Brasileiro de Cirurgiões, v. 34, p. 428-431, 2007.

COSTA, L. M. et al. Atual estado de proteção dos morcegos ameaçados de extinção no estado do Rio de Janeiro. Oecologia Australis, v. 23, n. 2, 2019.

FERREIRA, E. T. Avaliação do impacto e percepções de infrações contra a fauna terrestre em unidades de conservação estaduais de proteção integral do Rio de Janeiro. Orientadora: Solange de Vasconcellos Albuquerque Pessoa; 2015. 84 f. Dissertação (Mestrado Profissional em Biodiversidade em Unidades de Conservação) Instituto de Pesquisas Jardim Botânico do Rio de Janeiro/Escola Nacional de Botânica Tropical, Rio de Janeiro, 2015.

FLOR, B. A. S; LIMA, W. V; OLIVEIRA, I. N.; SOUZA, A. R; SEIXAS FILHO, J. T.de. Ecologia urbana e relações socioambientais nas áreas da cachoeira véu da noiva no município de Mangaratiba - Costa Verde, In: DE SEIXAS FILHO; J. T.; DA SILVA, C. A. F. (Orgs) IV Seminário das águas -Cachoeiras do Rio de Janeiro- Rio de Janeiro. Anais [...] HP Comunicação Editora, p.33-53,2018.

GONÇALVES, L. C. Uanauna gen. nov., a new genus of fireflies endemic to the Brazilian Atlantic forest (Coleoptera: Lampyridae), with key to brazilian genera of Lucidotina. Zootaxa, v. 4585, n. 1, p. 59-72, 2019.

GONZAGA, M. R. Avaliação da influência de pagamentos por serviços ambientais sobre a estrutura da paisagem. Orientador:Victor Eduardo Lima Ranieri. 2016, 173f. Dissertação (Mestrado em Ciências da Engenharia Ambiental) Escola de Engenharia de São Carlos, Universidade de São Paulo, São Paulo, 2016.

INEA. Educação Ambiental: Conceitos e práticas na Gestão Ambiental Pública. Rio de Janeiro,2014.

INEA. Plano de Manejo do Parque Estadual Cunhambebe. Rio de Janeiro,2015.

INEA, Relatório sobre políticas, planos, programas e projetos setoriais que incidem sobre a gestão dos recursos hídricos da Baía da Ilha Grande. Rio de Janeiro, 2018.

LIMA, M. S. C. S.; PEDERASSI, J.; SOUZA, C. A. S. Habitat use by the pumpkin toadlet, Brachycephalus ephippium (Anura, Brachycephalidae), in the Atlantic Rain Forest of Brazil. Boletín de la Asociación Herpetológica Española, v. 24, n. 2, p. 11-15, 2013.

LIMA, P. M. de. Avaliação dos programas de Educação Ambiental nas escolas municipais de Itaguaí no entorno do Parque Estadual Cunhambebe-RJ. Monografia (Curso de Engenharia Florestal) Instituto de Florestas da Universidade Federal Rural do Rio de Janeiro, Rio de Janeiro,2017. 
MARTINS, D. G.; LOPES, C. O.; NOGUEIRA, C.; NASCIMENTO, D. F. S. Educação Ambiental e a Interdisciplinaridade: Um relato de experiência no Vale do Rio Sahy. In: XI Simpósio Pedagógico e Pesquisas em Educação, ResendeRio de Janeiro. Anais [...] Ed. AEBD, 2018.

MATIAS, R. M. Avaliação da Sustentabilidade hídrica em pequenas bacias hidrográficas: o caso de Mangaratiba, RJ. Monografia (Graduação em Ciência Ambiental) Universidade Federal Fluminense, Instituto de Geociências, Niterói, 2016.

MMA. Estratégia Nacional de Comunicação e Educação Ambiental. Distrito Federal, 2006.Disponível em: $<$ https://www.icmbio.gov.br/portal/images/stories/comunicacao/publicacao ence a.pdf>. Acesso em 20 de julho de 2021.

MAURENZA, D. et. al. Lista da flora das Unidades de Conservação estaduais do Rio de Janeiro. Rio de Janeiro: Andrea Jakobsson Estúdio, 2018.

OLIVEIRA, A. C. M. A avaliação da efetividade de gestão dos Mosaicos de Áreas Protegidas do Rio de Janeiro. Orientadora: Camila Gonçalves de Oliveira. 2017. 160 f. Dissertação (Mestrado em Práticas em Desenvolvimento Sustentável) Universidade Federal Rural do Rio de Janeiro, PPGDS, Rio de Janeiro, 2017.

OLIVEIRA, A. L. A. et al. Inovação em Educação Ambiental: Um Estudo de caso sobre a trilha dos sentidos do Parque Estadual Mata do Limoeiro. Revista Brasileira de Educação Ambiental, v.16, n. 3, p. 429 - 438, 2021.

RAMALHO, E. M. M.; GODINHO, B. V.; COELHO JUNIOR, M.G.; CUNHA, S. M. D. O. Percepção dos professores das escolas no entorno do Parque Estadual Cunhambebe no município de Mangaratiba- RJ. In: SEABRA, G. (Org.) Terra- Políticas Públicas e Cidadania. Ituiutaba: Barlavento, p.11561168, 2019.

RAMOS, C. Memórias e ausências nas veredas do passado: a Estrada de Mangaratiba a São João do Príncipe como monumento histórico ambiental. In: BEM, J. S.; BERND, Z. (Orgs). Jornadas Mercosul: Memória, Ambiente e Patrimônio. Canoas, RS: Unilasalle, p.239-250, 2013.

RAMOS, A. et al. Revisão Sistemática de Literatura: contributo para a inovação na investigação em Ciências da Educação. Revista Diálogo Educacional, v. 14, n. 41, pp. 17-36, 2014 Pontifícia Universidade Católica do Paraná. Paraná, Brasil.

RANGEL, L. A. Avaliação da trilha Sahy- Rubião no Parque Estadual Cunhambebe em Mangaratiba (RJ). Monografia (Curso de EspecializaçãoEscola Nacional de Ciências Estatísticas (IBGE). Curso Lato Sensu em Análise Ambiental e Gestão do Território, Rio de Janeiro, 2016.

RANGEL, L. de. A; BOTELHO, R. G. M. Análise ambiental da trilha SahyRubião no Parque Estadual Cunhambebe em Mangaratiba (RJ) por meio de um Protocolo de Avaliação Rápida. Geo UERJ, n. 30, p. 391-418, 2017. 
RANGEL, L. de. A.; GUERRA, A. J. T.; BOtelHO, R. G. M. Potencial Geoturístico em unidades de conservação da Costa Verde (estado do Rio de Janeiro): o Parque Nacional da Serra da Bocaina e o Parque Estadual Cunhambebe. Anais do $1^{\circ}$ Workshop ARTE \& Ciência: Reflexão Integrada na Paisagem. Rio de Janeiro, 2017.

RIO DE JANEIRO, Decreto Estadual no 41,358, de 13 de junho de 2008. Cria o Parque Estadual Cunhambebe e dá outras providências.

ROCHA, R. de. O.; ROCHA, M. B. Levantamento de Espécies Exóticas em Unidades de Conservação: o Caso do Estado do Rio de Janeiro. Research, Society and Development, v. 8, n. 10, p. e408101406, 2019.

ROCHA, R. de. O.; ROCHA, M. B. Estudo sobre espécies exóticas em unidades de conservação no estado do Rio de Janeiro. Anais do V Simpósio de Pesquisa da Mata Atlântica, Engenheiro Paulo de Frontin, Rio de Janeiro, FFP-UERJ, p.21-22, 2019.

ROSA, C. R. Uso público em parques estaduais do Rio de Janeiro: perspectivas e desafios para a prestação de serviços de apoio à visitação. Orientadora: Camila Gonçalves de Oliveira. 2017.128 f. Dissertação (Mestrado em Práticas em Desenvolvimento Sustentável). Instituto de Florestas, Universidade Federal Rural do Rio de Janeiro, Seropédica, RJ, 2017.

SANTOS, H. Q. S.; OLIVEIRA, S. D.; PASSOS, F. V. de. A. A percepção do visitante na cachoeira Véu das Noivas - Parque Estadual do Cunhambebe-RJ. Revista Acadêmica Observatório de Inovação do turismo, v. 13, n. 2, p. 7799, 2019.

SÁTYRO, M. B. Educação Patrimonial: Uma poderosa ferramenta para preservação de parques e sítios arqueológicos de Mangaratiba. 2013. Monografia (Pós- Graduação Lato Sensu em Arqueologia Brasileira). Faculdade Redentor, Instituto de Arqueologia Brasileira, Rio de Janeiro, RJ, 2013.

SOUZA, K. R. G. Territórios de risco do Parque Estadual Cunhambebe na serra do mar. Anais do III Simpósio Ibero-Afro-Americano de Riscos: riscos e sociedade: da apropriação do espaço à criação de territórios em riscos. Uberlândia, Minas Gerais, UFU, p. 309-314, 2019.

SOUZA M. T.; SILVA M. D.; CARVALHO, R. Revisão integrativa: o que é e como fazer. Einstein, v. 8, n. 1, p. 102-6, 2010.

TORRACO, R. J. Writing integrative literature reviews: Guidelines and examples. Human Resource Development Review, v. 4, n. 3, p. 356-367, 2005.

VIANA, D. P. C.; UMBELINO, L. F. O conselho gestor como ferramenta para a gestão participativa de unidades de conservação. Revista Ibero-Americana de Ciências Ambientais, v. 7, n. 3, p. 40-58, 2016.

WHITTEMORE, R.; KNAFL, K. The integrative review: updated methodology. Journal of Advanced Nursing, v. 52, n. 5, p. 546-553, 2005. 